\title{
Late Radiation Outcomes of Patients with Newly Diagnosed Glioblastoma Treated with Accelerated Hyperfractionated Radiotherapy and Temozolomide
}

\author{
(D) Şefika Arzu ERGEN, 1 (D) Rasim MERAL, 2 (D) Musa ALTUN² \\ 'Department of Radiation Oncology, İstanbul University-Cerrahpaşa, Cerrahpaşa Faculty of Medicine, İstanbul-Turkey \\ ${ }^{2}$ Department of Radiation Oncology, İstanbul University, İstanbul Faculty of Medicine, İstanbul-Turkey
}

\begin{abstract}
OBJECTIVE
This study aimed to evaluate the late radiation outcomes in patients with glioblastoma who were treated with accelerated hyperfractionated radiotherapy (AHRT) and concurrent plus adjuvant temozolomide (TMZ).

\section{METHODS}

Between 2006 and 2007, 32 consecutive patients with glioblastoma were treated with AHRT and TMZ. The total dose of 66 Gy was administered in 33 fractions within 6 weeks. In phase I, PTV1 received 40 Gy (2 Gy per fraction, five times per week). In phase II, 26 Gy was delivered to PTV2 by adding a second daily fraction at intervals of 8 hours once every 3 days. All patients received chemotherapy according to the Stupp protocol. Toxicities were evaluated based on the CTCAE v3.0.

\section{RESULTS}

The median follow-up period was 18 months. A total of 28 patients completed the planned radiotherapy schedule, and 20 patients received six cycles of adjuvant TMZ. Median overall survival (OS) and progression-free survival (PFS) were 17 and 10 months, respectively. In univariate analysis, age, performance status, and RPA classes III-IV were found significant for OS. Multivariate analysis showed that six cycles of TMZ administration affected both OS and PFS. Late grade- 4 central nervous system (CNS) toxicities were observed in five patients.
\end{abstract}

\section{CONCLUSION}

It was observed that it is both feasible and effective to administer AHRT with TMZ in a selected group of patients. It provides better short-term survival advantage than the standard treatment regimen.

Keywords: Accelerated hyperfractionation; glioblastoma; radiotherapy; temozolomide.

Copyright $\odot$ 2019, Turkish Society for Radiation Oncology

\section{Introduction}

In adults, glioblastoma (GB) is the most common malignant glial tumor. It has a median survival period of 12-18 months. [1,2] Radiotherapy (RT) plays an important role in the treatment of GB.[2,3] Walker et al. have shown that postoperative RT doubled the survival as compared to that of supportive treatment.[4] After six randomized studies, postoperative RT was accepted as the standard component of treatment. [3-8] Many studies have investigated the role of chemotherapy; however, the effect in the majority of these trials 
was limited.[9] In 2005, the European Organization for Research and Treatment of Cancer (EORTC) and National Cancer Institute of Canada intergroup trial demonstrated the improvement in survival with RT plus concurrent and adjuvant temozolomide (TMZ). Thus, for the first time, the benefit of systemic chemotherapy in GB was proved with a phase III study.[10]

The standard treatment for patients with newly diagnosed GB is wide surgical resection followed by postoperative RT and concurrent plus adjuvant chemotherapy. Despite the advancements in treatment modalities, the prognosis is still poor, and the five-year survival rate is below $10 \%$.[11] Efforts are being made to improve the results in GB with the developments in modern RT techniques after TMZ. Because of improved functional imaging methods and innovations in the RT techniques, better results can be obtained by raising the dose. Recently, different fractionation schemes and higher doses with intensity modulated radiation therapy (IMRT) or stereotactic radiosurgery (SRS) have been investigated.[12-20]

In this study, the late radiation results in patients with newly diagnosed GB who were treated with accelerated hyperfractionated RT and concurrent plus adjuvant TMZ were evaluated.

\section{Materials and Methods}

This was a prospective observational clinical study. It was approved by the ethics committee of Istanbul University, Istanbul Medical Faculty. Written informed consent was obtained from each patient before their participation.

\section{Patient Selection}

Between 2006 and 2007, 32 patients with newly diagnosed GB were enrolled in the study. Inclusion criteria for the patients were as follows: (a) histologically confirmed GB (WHO grade IV); (b) age between 18 and 70 years; (c) total or subtotal resection; (d) Karnofsky performance status (KPS) score $\geq 70 \%$; and (e) normal hematologic, renal, and hepatic parameters. Patients who had received prior RT to the brain and with recurrent disease or concurrent other malignancy were excluded.

\section{Treatment Characteristics}

All of the patients underwent surgery; 29 of them had (90.6\%) gross total resection, and 3 (9.4\%) of them had subtotal resection. RT started within 6 weeks after the surgical resection in $81 \%$ of the patients. During simulation and treatment, patient immobilization was provided with an individualized thermoplastic mask. The computed tomography simulation was made in the supine position with a $0.5-\mathrm{cm}$ thick slice. Initial clinical target volume 1 (CTV1) included the contrast-enhancing lesion and surrounding edema on the preoperative MRI with a $15-\mathrm{mm}$ margin. Then the field was reduced, and the volume of boost (CTV2) was defined as the area of contrast-enhancing lesion plus a $15-\mathrm{mm}$ margin. Planning target volumes were created by adding 5-mm margins to CTVs. Treatment plans were planned using the Three-Dimensional Conformal Radiotherapy Technique (3-D CRT). According to tumor location, radiation was delivered from three or four fields with 6-18 MV linear accelerators. The total dose of $66 \mathrm{~Gy}$ was administered in 33 fractions over 6 weeks. In the first phase of treatment, PTV1 received 40 Gy (2 Gy per fraction a day, five times a week). In phase II, the total dose was increased to $26 \mathrm{~Gy}$ by adding a second daily fraction at intervals of 8 hours once every 3 days.

All patients received concurrent TMZ $75 \mathrm{mg} / \mathrm{m} 2$ daily during RT. One month after completion of RT, according to the Stupp protocol, adjuvant TMZ was administered $150-200 \mathrm{mg} / \mathrm{m} 2$ daily for 5 days every 28 days.

\section{Follow-Up}

During chemoradiotherapy, patients were followed up for weekly blood count, and they were evaluated for acute toxicities. In addition, during adjuvant TMZ period, monthly follow-ups with blood tests and serum chemistries were conducted. A neurologic examination was also performed at each visit. Later on, follow-ups were conducted every 3 months for the first 2 years and every 6 months thereafter. A contrast-enhanced cranial MRI was performed 1 month after the end of RT and every 3 months thereafter. If radiation necrosis was suspected in patients, perfusion MRI or MR spectroscopy was performed. Disease progression is defined radiologically (a $25 \%$ or greater increase in the largest vertical diameter of a contrast-enhancing tumor on MRI, or a new lesion). In case of progression, each patient was re-evaluated for second-line treatment options such as surgery, RT, or chemotherapy. Treatment-related toxicities were graded according to the Common Terminology Criteria for Negative Events (CTCAE) 3.0.[21]

\section{Statistical Analysis}

Overall survival (OS) time was calculated from the date of diagnosis (biopsy or surgical resection) to the date of death from any cause. Progression-free survival (PFS) time was calculated from the date of diagnosis to the date of progression of the disease or to the time 
at which new lesions appeared. Survival analyses were performed according to the intention-to-treat principle. The Kaplan-Meier method was used to calculate the OS and PFS rates. In univariate analysis, the logrank test was used to compare survival according to different prognostic factors. A multivariate Cox regression analysis was used to determine prognostic factors affecting OS and PFS. For the statistical analysis, SPSS version 20 for Windows (IBM Corp., Armonk, NY) was used. The p-value $<0.05$ was accepted to be significant.

\section{Results}

\section{Patient Characteristics}

There were 18 male (56.3\%) and 14 female (43.8\%) patients. The median age was 56 years (range: $26-70$ years). On pre-treatment assessment, median KPS

Table 1 Clinical and tumor characteristics of all patients

\begin{tabular}{|c|c|}
\hline Characteristics & Number (\%) \\
\hline Age (year), Median(range) & $56(26-70)$ \\
\hline$\leq 50$ & $11(34)$ \\
\hline$>50$ & $21(66)$ \\
\hline \multicolumn{2}{|l|}{ Gender } \\
\hline Female & $14(43.8)$ \\
\hline Male & $18(56.3)$ \\
\hline \multicolumn{2}{|c|}{ Karnofsky Performance status (\%) } \\
\hline Median (range) & $90(70-100)$ \\
\hline \multicolumn{2}{|l|}{ RPA classes } \\
\hline III & $9(28)$ \\
\hline IV & $2(6)$ \\
\hline $\mathrm{V}$ & $21(66)$ \\
\hline \multicolumn{2}{|l|}{ Tumor location } \\
\hline Frontal lobe & $12(37.5)$ \\
\hline Temporal lobe & $8(25)$ \\
\hline Parietal lobe & $8(25)$ \\
\hline Others & $4(12.5)$ \\
\hline \multicolumn{2}{|l|}{ Resection } \\
\hline Gross Total & $29(90.6)$ \\
\hline Subtotal & $3(9.4)$ \\
\hline \multicolumn{2}{|l|}{ Concomitant TMZ } \\
\hline Yes & $30(93.7)$ \\
\hline No & $2(6.3)$ \\
\hline \multicolumn{2}{|l|}{ Adjuvant TMZ } \\
\hline 6 cycles & $20(62.5)$ \\
\hline 5 cycles & $2(6.2)$ \\
\hline 4 cycles & $3(9.3)$ \\
\hline 3 cycles & $1(3.1)$ \\
\hline None & $6(18.75)$ \\
\hline
\end{tabular}

Abbreviations: RPA: Recursive partitioning analysis; TMZ: Temozolomide score was $90 \%$. The most common tumor localization was the frontal lobe (37.5\%). The patient characteristics are listed in Table 1.

Of the 32 patients, 28 (87.5\%) completed the planned 66 Gy of RT dose. TMZ at $75 \mathrm{mg} / \mathrm{m} 2 /$ day was started concomitant with RT in all patients, but treatment was discontinued due to toxicities in two patients. Six cycles of adjuvant TMZ was completed in 20 patients $(62.5 \%)$. Six patients did not receive the adjuvant chemotherapy. One patient refused the treatment, one patient discontinued treatment due to grade IV pancytopenia, one patient died of pneumonia during $\mathrm{RT}$, and three patients died due to disease progression at the end of RT.

\section{Survival Outcomes and Prognostic Factors}

The median follow-up period was 18 months (range: 2-98 months). At the time of the analysis, all of the patients who participated in the study were dead. Only two patients lived longer than 5 years (96 and 98 months). The median OS time was 17 months. The OS rates from 1 to 5 years were $75 \%, 28.1 \%, 12.5 \%, 9.4 \%$, and $6.3 \%$, respectively (Fig. 1).

Distant metastasis or leptomeningeal disease was not observed in any patient. However, a local failure developed in all patients during follow-up. Salvage chemotherapy was given to 12 patients. Nine of them received TMZ, and the remaining three had fotemustine. Ten patients had best supportive care, five patients underwent re-operation, and one patient re-irradiated with stereotactic radiosurgery. The median PFS time was 10 months. The PFS rates at 1 and 2 year were $35.5 \%$ and $6.5 \%$, respectively (Fig. 2 ).

In univariate analyses, the age ( $\leq 50$ years) $(\mathrm{p}=0.011)$, RPA classes III-IV ( $\mathrm{p}=0.011)$, KPS $\geq 90(\mathrm{p}=0.013)$, and

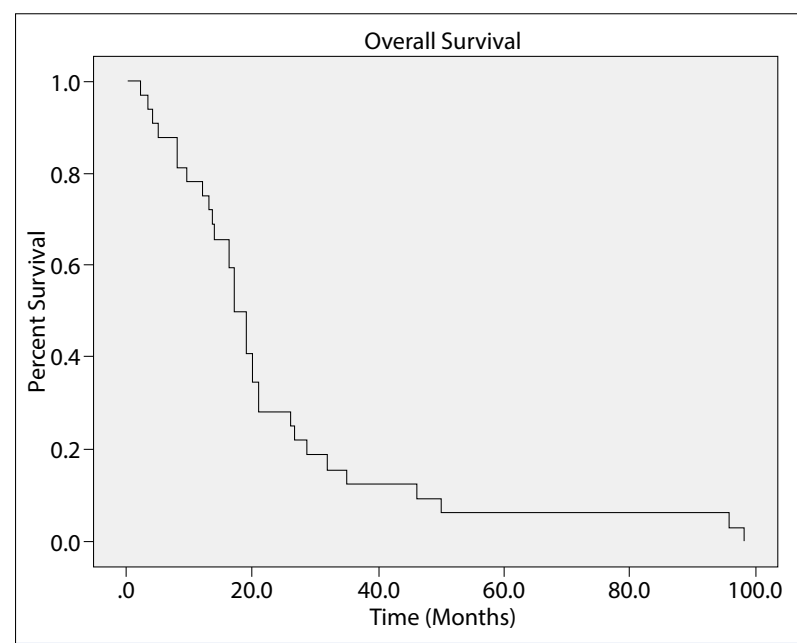

Fig. 1. Overall survival for all patients. 


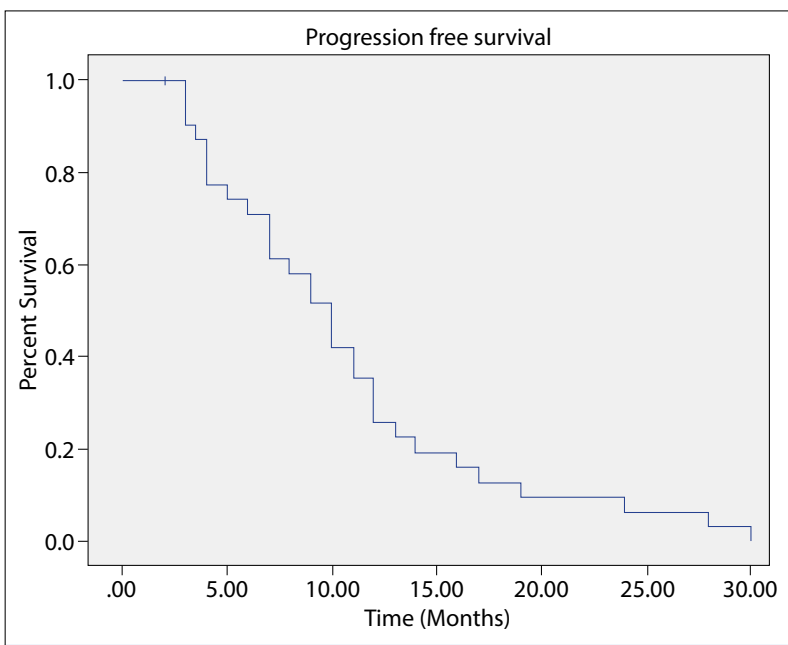

Fig. 2. Progression free survival for all patients.

use of six cycles of adjuvant TMZ $(\mathrm{p}<0.0001)$ were found as significant prognostic factors for OS. The PFS rate was significantly higher in patients who received six cycles of adjuvant TMZ compared to that in patients who received less than six cycles (11 vs. 4 months, $\mathrm{p}<0.001$ ) (Table 2).

In multivariate analysis, only the use of adjuvant six cycles of TMZ was found to be the most important prognostic factor for both the OS $(\mathrm{p}=0.003)$ and PFS $(\mathrm{p}=0.005)$ (Table 3).

\section{Acute and Late Toxicity}

The most commonly developed acute side effect during chemoradiotherapy was hematologic toxicity. Grade- 4 toxicity was observed in eight patients. Six patients had grade- 4 lymphopenia, one patient had grade- 4 leukopenia, and one patient had grade- 4 thrombocytopenia. Furthermore, fatigue was observed as the most common non-hematologic toxicity (Table 4). Pneumonia developed in one patient. During the adjuvant TMZ period, moderate nausea and vomiting, as well as grade 2-3 lymphopenia and thrombocytopenia developed. Deep vein thrombosis was observed in two patients, and pulmonary embolism was observed in two patients.

As a late toxicity, radiation necrosis was detected in $12(42.8 \%)$ patients after median 12.5 months from RT. Radiation necrosis was diagnosed with radiological imaging in ten patients and with biopsy in two patients. However, most of the patients were asymptomatic, only one patient had grade- 3 necrosis, and the other had grade- 4 necrosis. In addition, other late grade 3-4 central nervous system (CNS) toxicities included visual loss in two patients, somnolence in one patient, cognitive disturbance in one patient, and memory impair-

Table 2 Analysis of potential predictive factors affecting overall survival (OS) and progression-free survival (PFS) in univariate analysis

\begin{tabular}{|c|c|c|c|c|c|c|c|}
\hline \multirow[b]{2}{*}{ Variables } & \multirow[b]{2}{*}{$\mathbf{N}$} & \multicolumn{2}{|c|}{ OS rates (\%) } & \multirow[b]{2}{*}{$\mathbf{p}$} & \multicolumn{2}{|c|}{ PFS rates (\%) } & \multirow[b]{2}{*}{$\mathbf{p}$} \\
\hline & & 2-years & 5-years & & 1-year & 2-years & \\
\hline \multicolumn{8}{|l|}{ Age } \\
\hline$\leq 50$ & 11 & 45.5 & 18.2 & 0.011 & 36.4 & 9.1 & 0.224 \\
\hline$>50$ & 21 & 19 & 0 & & 30 & 5.5 & \\
\hline \multicolumn{8}{|l|}{ Gender } \\
\hline Female & 14 & 28.6 & 0 & 0.518 & 38.5 & 7.4 & 0.997 \\
\hline Male & 18 & 27.8 & 11.1 & & 27.8 & 5.6 & \\
\hline \multicolumn{8}{|l|}{ RPA class } \\
\hline III-IV & 11 & 45.5 & 18.2 & 0.011 & 36.4 & 9.1 & 0.224 \\
\hline V & 21 & 19 & 0 & & 30 & 5 & \\
\hline \multicolumn{8}{|l|}{ KPS (\%) } \\
\hline$\geq 90$ & 18 & 38.9 & 11.1 & 0.013 & 44.4 & 5.6 & 0.352 \\
\hline$<90$ & 14 & 14.3 & 0 & & 23.1 & 7.7 & \\
\hline \multicolumn{8}{|l|}{ Surgery - RT interval } \\
\hline$<6$ weeks & 25 & 28 & 4 & 0.379 & 37.5 & 8.3 & 0.607 \\
\hline$\geq 6$ weeks & 7 & 28.6 & 0 & & 28.6 & 0 & \\
\hline \multicolumn{8}{|l|}{ Adjuvant TMZ } \\
\hline Less than six cycles & 12 & 0 & 0 & $<0.0001$ & 9.1 & 0 & $<0.0001$ \\
\hline Six cycles & 20 & 45 & 10 & & 50 & 10 & \\
\hline
\end{tabular}

Abbreviations: N: Number of patients; RPA: Recursive partitioning analysis; KPS: Karnofsky performance status; RT: Radiotherapy; TMZ: Temozolomide 
Table 3 Analysis of potential predictive factors affecting overall survival and disease-free survival in multivariate analysis

\begin{tabular}{|c|c|c|c|c|c|c|}
\hline \multirow[b]{2}{*}{ Variables } & \multirow[b]{2}{*}{ HR } & \multirow{2}{*}{$\begin{array}{c}\text { OS } \\
95 \% \mathrm{Cl}\end{array}$} & \multirow[b]{2}{*}{$\mathbf{p}$} & \multirow[b]{2}{*}{ HR } & \multirow{2}{*}{$\begin{array}{l}\text { PFS } \\
95 \%\end{array}$} & \multirow[b]{2}{*}{$\mathbf{p}$} \\
\hline & & & & & & \\
\hline \multicolumn{7}{|l|}{ Age } \\
\hline$(\leq 50$ vs. $>50)$ & 0.59 & $0.225-1.575$ & 0.296 & 0.884 & $0.350-2.236$ & 0.795 \\
\hline \multicolumn{7}{|l|}{ RPA classes } \\
\hline (III-IV.vs.V) & 0.95 & $0.242-1.576$ & 0.344 & 1.5 & $0.264-9.375$ & 0.654 \\
\hline \multicolumn{7}{|l|}{ KPS (\%) } \\
\hline$(\geq 90$ vs. $<90)$ & 0.459 & $0.203-1.037$ & 0.061 & 1.378 & $0.632-3.002$ & 0.420 \\
\hline \multicolumn{7}{|l|}{ Adjuvant TMZ } \\
\hline ( 6 cycles vs. $<6$ cycles) & 0.235 & $0.090-0.614$ & 0.003 & 0.065 & $1.527-10.240$ & 0.005 \\
\hline
\end{tabular}

Abbreviations: RPA: Recursive partitioning analysis; KPS: Karnofsky performance status; TMZ: Temozolomide

Table 4 Acute toxicity

\begin{tabular}{lllll} 
& \multicolumn{5}{c}{ Grade } \\
\cline { 2 - 5 } Toxicity & 1 & 2 & 3 & 4 \\
\hline
\end{tabular}

Hematologic

$\begin{array}{lllll}\text { Anemia } & 2 & 1 & 0 & 0\end{array}$

$\begin{array}{lllll}\text { Thrombocytopenia } & 1 & 1 & 1 & 1\end{array}$

$\begin{array}{lllll}\text { Leukopenia } & 2 & 1 & 1 & 1\end{array}$

$\begin{array}{lllll}\text { Lymphopenia } & 6 & 2 & 3 & 6\end{array}$

Gastrointestinal

$\begin{array}{lllll}\text { Nausea } & 5 & 2 & 0 & 0\end{array}$

Vomiting

Hepatotoxicity

AST

ALT

Others

$\begin{array}{lllll}\text { Fatigue } & 12 & 5 & 0 & 0\end{array}$

Dermatitis

18

Table 5 Late toxicities according to CTCAE v 3.0

\begin{tabular}{|c|c|c|c|c|c|c|}
\hline \multirow[t]{2}{*}{ Toxicity } & \multirow{2}{*}{$\begin{array}{c}\text { No. of } \\
\text { patients (\%) }\end{array}$} & \multicolumn{5}{|c|}{ Grade } \\
\hline & & 1 & 2 & 3 & 4 & 5 \\
\hline $\begin{array}{l}\text { Radiation } \\
\text { necrosis }\end{array}$ & $\begin{array}{c}12 \\
(42.8)\end{array}$ & 6 & 4 & 1 & 1 & 0 \\
\hline $\begin{array}{l}\text { Cognitive } \\
\text { disturbance }\end{array}$ & $\begin{array}{c}19 \\
(67.8)\end{array}$ & 6 & 12 & 0 & 1 & 0 \\
\hline $\begin{array}{l}\text { Memory } \\
\text { impairment }\end{array}$ & $\begin{array}{c}12 \\
(42.8)\end{array}$ & 7 & 4 & 1 & 0 & 0 \\
\hline Somnolence & $\begin{array}{c}7 \\
(25)\end{array}$ & 0 & 6 & 0 & 1 & 0 \\
\hline Retinopathy & $\begin{array}{c}2 \\
(7.1)\end{array}$ & 0 & 0 & 0 & 2 & 0 \\
\hline
\end{tabular}

ment in one patient (Table 5). Grade-5 CNS toxicity did not develop in any patient.

\section{Discussion}

Although GB is treated with a multimodal approach, it still has the worst prognosis among malignant glial tumors.[1-3,11] Surgical resection is one of the primary treatment modalities, and the extent of surgical intervention is an important prognostic factor for survival. [22-24] However, maximal safe resection is not always possible due to the performance status of the patient and the tumor localization. Furthermore, even if the tumor is removed by extensive resection, the neoplastic cells may remain in the adjacent normal tissues due to the infiltrative nature of the tumor, and they may repopulate. Therefore, RT is needed to eradicate residual cells. As compared to chemotherapy after surgery or surgery alone, randomized trials have shown that adjuvant RT is more effective on survival $[1,3]$ The Brain Tumor Study Group (BTSG) 69-01 showed that median OS was 3.5 months in patients receiving only supportive care after surgery, whereas the median survival was extended to 9 months in patients who received postoperative RT.[4]

GB is a highly radio-resistant tumor. In the preclinical studies, it has been reported that high doses $(\geq 80$ Gy) are required to eliminate malignant glial cells. [25] Moreover, early clinical trials have shown a relationship between dose and survival. Walker et al. reported that the median survival improved from 13.5 weeks to 42 weeks when the radiation dose was increased from 45 Gy to 60 Gy.[26] In addition, Reni et al. found that doses above 60 Gy were associated with increased survival.[27]

The current standard dose used in GB treatment is $60 \mathrm{~Gy}$. However, in follow-ups, the most common problem is still a local failure, and most of the recurrences develop within the high-dose area.[28,29] The 
administered dose is probably insufficient. To date, a number of dose-escalation trials have been conducted to improve the local control using different techniques such as altered fractionation, stereotactic radiosurgery, brachytherapy, or IMRT.[12,15-20,30-35]

Increasing the treatment dose by altered fractionation has been used for a long time in rapidly growing tumors. The aim is to exploit radiobiological advantages. In this way, the total radiation dose is increased without prolonging the duration of the treatment and without excessive late toxicity. Thus, repopulation is prevented. For this reason, hyperfractionation was frequently used in the early dose-escalation trials. However, most of these studies have failed, and no survival advantage has been demonstrated compared to standard conventional fractionation. [35-38] Unlike, Fitzek et al. reported that median survival was prolonged to 20 months in patients receiving 90 cobalt Gy equivalent doses with accelerated fractionated proton/photon therapy.[39]

Most of the above-mentioned studies have been performed before the TMZ period. In 2005, Stupp et al. showed a remarkable improvement in survival with the addition of TMZ in GB treatment, and they opened a new era.[10] After the use of TMZ with RT became standard in GB management, RT dose-escalation studies have been accelerated again to improve survival further.[13,16-18,32,33,40,41]

Kaul et al. compared 64 patients who underwent accelerated hyperfractionated RT with 67 patients who underwent conventional RT, and they found no significant difference between the two groups.[40] Similarly, Badiyan et al. failed to show improvement in survival rate in patients who received high-dose RT with TMZ compared to those who received the standard-dose RT.[41] On the other hand, Massaccessi et al. performed a dose-escalation study by using the simultaneous integral boost (SIB) IMRT technique, and they reported that 70 Gy delivered in 25 fractions with TMZ was well tolerated.[16] In addition, a study in Japan reported that the median survival was extended to 21.6 months in patients treated with hyperfractionated concomitant boost proton RT of $96.6 \mathrm{GyE}$ in 56 fractions. [42]

In this study, the total radiation dose was increased to 66 Gy with accelerated hyperfractionation. The 1 -year and 2-year OS rates were found as $75 \%$ and $28.1 \%$, respectively. In addition, the median OS time was 17 months, and the median PFS time was 10 months. Whereas, in the Stupp's trial, the 1-year and 2 -year OS rates were reported as $61.1 \%$ and $26.5 \%$, re- spectively. There was a median 2.5-month survival advantage according to this trial. But the 5-year survival rates are similar.

In this study, it was observed that patients with good performance status and younger age ( $\leq 50$ years) have a higher survival rate. These findings are consistent with the prognostic factors mentioned in previous trials. Also, the RPA model, which was defined as a prognostic factor by Curran et al., showed well correlation with survival rates in our study.[43] Patients with RPA class III-IV had 5-month survival advantage over those with RPA class V ( $\mathrm{p}=0.036)$. Furthermore, in multivariate analysis, the use of six cycles of adjuvant TMZ was found to be independent prognostic factors for both OS and PFS.

In several AHRT trials, it has been reported that the duration of treatment can be safely shortened with acceptable acute and late toxicities.[39,44,45] However, late toxicities related to radiation in this study were found to be slightly higher than those in the literature. The use of 3-D CRT and the volume of the normal tissue exposed to radiation are larger because CTV1 contains peritumoral edema. As a matter of fact, currently the target volume has been reduced in the EORTC protocol, and the incidences of toxicities have decreased with the widespread use of IMRT.[46,47]

On the other hand, radio-necrosis is regarded as a favorable event in terms of survival by some researchers. A correlation between radio-necrosis and improved outcomes has been shown in some series. $[39,48-50]$ For example, Peca et al. reported that a median OS was 32 months in patients with radio-necrosis, whereas it was 10 months in patients with tumor progression.[50] However, there was no significant relationship between radio-necrosis and survival in our series $(\mathrm{p}=0.2)$.

There are some limitations in this study. First, the number of patients investigated was small, and they were retrospectively assessed. Secondly, since the study was conducted about 10 years ago, the MGMT methylation status of the patients was unknown. Thirdly, while dose-intensification studies of today are conducted with modern RT techniques such as IMRT, 3-D CRT was used in our study at that time. However, the positive aspect of the study is that all patients were followed up to death, and long-term results were presented.

\section{Conclusion}

In conclusion, RT is one of the most important treatment modalities in high-grade gliomas after resection. 
Our results show that accelerated hyperfractionated $\mathrm{RT}$ and TMZ are feasible, and they improve survival in a selected group of patients. However, it causes a slight increase in late neurotoxicity. In future, it may be possible to achieve the desired results in studies performed using advanced RT and functional imaging techniques, with the combination of new targeted agents.

Peer-review: Externally peer-reviewed.

Conflict of Interest: No conflict of interest was declared by the authors.

Ethics Committee Approval: This study was approved by the Ethics Committee of İstanbul University, İstanbul Medical Faculty.

Financial Support: None declared.

Authorship contributions: Concept - R.M., M.A., Ş.A.E.; Design - R.M., Ş.A.E., M.A.; Supervision - R.M., M.A.; Materials - Ş.A.E., R.M., M.A.; Data collection \&/or processing - Ş.A.E.; Analysis and/or interpretation - Ş.A.E., R.M.; Literature search - Ş.A.E.; Writing - Ş.A.E., R.M.; Critical review - R.M., M.A.

\section{References}

1. Lassman AB, Schifter D, Corn BW. High-Grade Gliomas. In: Gunderson LL, Tepper JE, editors. Clinical Radiation Oncology. 3th edition. Philadelphia: Elsevier Churchill Livingstone; 2012. p. 461-72.

2. Wick W, Osswald M, Wick A, Winkler F. Treatment of glioblastoma in adults. Ther Adv Neurol Disord 2018;11:1-13.

3. Laperriere N, Zuraw L, Cairncross G; Cancer Care Ontario Practice Guidelines Initiative Neuro-Oncology Disease Site Group. Radiotherapy for newly diagnosed malignant glioma in adults: a systematic review. Radiother Oncol 2002;64(3):259-73.

4. Walker MD, Alexander E Jr, Hunt WE, MacCarty CS, Mahaley MS Jr, Mealey J Jr, et al. Evaluation of BCNU and/or radiotherapy in the treatment of anaplastic gliomas. A cooperative clinical trial. J Neurosurg 1978;49(3):333-43.

5. Scally TS, Lin C, Beriwal S, Brady LW. Central Nervous System Tumors. In: Perez CA, Brady LW, Halperin EC, Schmidt-Ullrich RK, editors. Principles and Practise of Radiation Oncology. 4th edition. Philadelphia: Lippincoth Williams \& Wilkins; 2004. p. 810-5.

6. Shapiro WR, Young DF. Treatment of malignant glioma. A controlled study of chemotherapy and irradiation. Arch Neurol 1976;33(7):494-500.

7. Walker MD, Green SB, Byar DP, Alexander E Jr, Batzdorf U, Brooks WH, et al. Randomized comparisons of radiotherapy and nitrosoureas for the treatment of malignant glioma after surgery. $\mathrm{N}$ Engl J Med 1980;303(23):1323-9.

8. Sandberg-Wollheim M, Malmström P, Strömblad LG, Anderson H, Borgström S, Brun A, et al. A randomized study of chemotherapy with procarbazine, vincristine and lomustine with and without radiation therapy for astrocytoma grades 3 and/or 4 . Cancer 1991;68(1):22-9.

9. Fine HA, Dear KB, Loeffler JS, Black PM, Canellos GP. Meta-analysis of radiation therapy with and without adjuvant chemotherapy for malignant gliomas in adults. Cancer 1993;71(8):2585-97.

10. Stupp R, Mason WP, Bent MJ, Weller M, Fisher B, Taphoorn MJB, et al. for the European organization for Research and Treatment of Cancer Brain Tumor and Radiotherapy Groups and the National Cancer Institue of Canada Clinical Trials Group. Radiotherapy plus concomitant and adjuvant temozolomide for glioblastoma. N Eng J Med 2005;352(10):987-95.

11. Stupp R, Hegi ME, Mason WP, van den Bent MJ, Taphoorn MJ, Janzer RC, et al; European Organisation for Research and Treatment of Cancer Brain Tumor and Radiation Oncology Groups; National Cancer Institute of Canada Clinical Trials Group. Effects of radiotherapy with concomitant and adjuvant temozolomide versus radiotherapy alone on survival in glioblastoma in a randomised phase III study: 5-year analysis of the EORTCNCIC trial. Lancet Oncol 2009;10(5):459-66.

12. Raymond VP, Souhami L, Roberge D, Kavan P, Shakibnia L, Muanza T, et al. Accelerated hypofractionated intensity-modulated radiotherapy with concurrent and adjuvant temozolomide for patients with glioblastoma multiforme: a safety and efficacy analysis. Int J Radiat Oncol Biol Phys 2009;73(2):473-8.

13. Tsien CI, Brown D, Normolle D, Schipper M, Piert M, Junck L, et al. Concurrent temozolomide and dose-escalated intensity modulated radiation therapy in newly diagnosed glioblastoma. Clin Cancer Res 2012;18(1):273-9.

14. Cho KH, Kim JY, Lee SH, Yoo H, Shin SH, Moon SH, et al. Simultaneous integrated boost intensity modulated radiotherapy in patients with high grade gliomas. Int J Radiat Oncol Biol Phys 2010;78(2):390-7.

15. Ciammella P, Galeandro M, D’Abbiero N, Podgornii A, Pisanello A, Botti A, et al. Hypo-fractionated IMRT for patients with newly diagnosed glioblastoma multiforme: a 6 year single institutional experience. Clin Neurol Neurosurg 2015;115(9):1609-14.

16. Massaccesi M, Ferro M, Cilla S, Balducci M, Deodato F, Macchia G, et al. Accelerated intensity-modulated radiotherapy plus temozolomide in patients with glioblastoma: a phase I dose-escalation study (ISIDEBT-1). Int J Clin Oncol 2013;18:784-91. 
17. Reddy K, Damek D, Gaspar LE, Ney D, Waziri A, Lillehei K, et al. Phase II trial of hypofractioated IMRT with temozolomide for patients with newly diagnosed glioblastoma multiforme. Int J Radiat Oncol Biol Phys 2012;84(3):655-60.

18. Watkins JM, Marshall DT, Patel S, Giglio P, Herrin AE, Garret-Mayer E, et al. High dose radiotherapy to 78 Gy with or without temozolomide for high grade gliomas. J Neurooncol 2009;93(3):343-8.

19. Tsao MN, Mehta MP, Whelan TJ, Morris DE, Hayman JA, Flickinger JC, et al. The American Society for Therapeutic Radiology and Oncology (ASTRO) evidencebased review of the role of radiosurgery for malignant glioma. In. J Radiat Oncol Biol Phys 2005;63(1):47-55.

20. Souhami L, Seiferheld W, Brachman D, Podgorsak EB, Werner-Wasik M, Lustig R, et al. Randomized comparison of stereotactic radiosurgery followed by conventional radiotherapy with carmustine to conventional radiotherapy with carmustine for patients with glioblastoma multiforme: report of Radiation Therapy Oncology Group 93-05 protocol. Int J Radiat Oncol Biol Phys 2004;60(3):853-60.

21. CTCAEv3.0. The revised common toxicity criteria: Version 3.0. 2006. Available at: https://ctep.cancer.gov/ protocoldevelopment/electronic_applications/docs/ ctcaev3.pdf. Accessed February 15, 2019.

22. Nitta T, Sato K. Prognostic implications of the extent of surgical resection in patients with intracranial malignant gliomas. Cancer 1995;75(11):2727-31.

23. Fults DW. Neurosurgeons still wanted. Neuro Oncol 2018;20(9):1150-1.

24. Mirimanoff RO, Gorlia T, Mason W, Van den Bent MJ, Kortmann RD, Fisher B, et al. Radiotherapy and temozolomide for newly diagnosed glioblastoma: recursive partitioning analysis of the EORTC 26981/22981NCIC CE3 phase III randomized trial. J Clin Oncol 2006;24(16):2563-9.

25. Taghian A, Dubois W, Budach W, Baumann M, Freeman J, Suit H. Invivo radiation sensitivity of glioblastoma multiforme. Int J Radiat Oncol Biol Phys 1995;32:99-104.

26. Walker MD, Strike TS, Sheline GE. An analysis of dose-effect relationship in the radiotherapy of malignant gliomas. Int J Radiat Oncol Biol Phys 1979;5(10):1725-31.

27. Reni M, Cozzarini C, Panucci MG, Ceresoli GL, Ferreri AJ, Fiorino $C$, et al. Irradiation fields and doses in glioblastoma multiforme: are current standards adequate? Tumori 2001;87(2):85-90.

28. Sherriff J, Tamangani J, Senthil L, Cruickshank G, Spooner D, Jones B, et al. Patterns of relapse in glioblastoma multiforme following concomitant chemoradiotherapy with temozolomide. Br J Radiol 2013;86(1022):20120414.
29. Wick W, Stupp R, Beule AC, Bromberg J, Wick A, Ernemann U, et al; European Organisation for Research and Treatment of Cancer and the National Cancer Institute of Canada Clinical Trials Group. A novel tool to analyse MRI recurrence patterns in glioblastoma. Neuro Oncol 2008;10(6):1019-24.

30. Shrieve DC, Alexander E 3rd, Black PM, Wen PY, Fine HA, Kooy HM, et al. Treatment of patients with primary glioblastoma multiforme with standart postoperative radiotherapy and radiosurgical boost: prognostic factors and long term outcome. J Neurosurg 1999;90(1):72-7.

31. Prisco FE, Weltman E, de Hanriot RM, Brandt RA. Radiosurgical boost for primary high-grade gliomas. J NeuroOncol 2002;57(2):151-60.

32. Fariselli L, Cuppini L, Gaviani P, Marchetti M, Pinzi V, Milanesi I, et al. Short course radiotherapy concomitant with temozolomide in GBM patients: a phase II study. Tumori. 2017;103(5):457-63.

33. Scoccianti S, Krengli M, Marrazzo L, Magrini SM, Detti B, Fusco V, et al. Hypofractionated radiotherapy with simultaneous integrated boost (SIB) plus temozolomide in good prognosis patients with glioblastoma: a multicenter phase II study by the Brain Study Group of the Italian Association of Radiation Oncology (AIRO). Radiol Med 2018;123(1):48-62.

34. Monjazeb AM, Ayala D, Jensen C, Case LD, Bourland JD, Ellis TL, et al. A phase I dose escalation study of hypofractionated IMRT field-in-field boost for newly diagnosed glioblastoma multiforme. Int J Radiat Oncol Biol Phys 2012;82(2):743-8.

35. Nelson DF, Curran WJ Jr., Scott C, Nelson JS, Weinstein AS, Ahmad K, et al. Hyperfractioned radiation therapy and bischlorethyl nitrosourea in the treatment of malignant glioma-possible advantage observed at 72.0 Gy in 1.2 Gy B.I.D. fractions: report of the Radiation Therapy Oncology Group Protocol 8302. Int J Radiat Oncol Biol Phys 1993;25(2):193-207.

36. Nelson DF, Diener-West M, Horton J, Chang CH, Schoenfeld D, Nelson JS. Combined modality approach to treatment of malignant gliomas--re-evaluation of RTOG 7401/ECOG 1374 with long-term follow-up: a joint study of the Radiation Therapy Oncology Group and the Eastern Cooperative Oncology Group. NCI Monogr 1988;(6):279-84.

37. Murray KJ, Nelson DF, Scott C, Fishbach J, Porter A, Farnan N, et al. Quality-adjusted survival analysis of malignant glioma. Patients treated with twice daily radiation (RT) and carmustine: a report of Radiation Therapy Oncology Group (RTOG) 83-02. Int J Radiat Oncol Biol Phys 1995;31(3):453-9.

38. Nieder C, Nestle U, Ketter R, Kolles H, Gentner SJ, Steudel WI, et al. Hyperfractionated and acceleratedhyperfractionated radiotherapy for glioblastoma multiforme. Radiat Oncol Invest 1999;7(1):36-41. 
39. Fitzek MM, Thornton AF, Rabinov JD, Lev MH, Pardo FS, Munzenrider JE, et al. Accelerated fractionated proton/photon irradiation to 90 cobalt gray equivalent for glioblastoma multiforme: Results of a phase II prospective trial. J Neurosurg 1999;91(1):251-60.

40. Kaul D, Florange J, Badakhshi H, Grün A, Ghadjar P, Exner S, et al. Accelerated hyperfractionation plus temozolomide in glioblastoma. Radiat Oncol 2016;11:70-7.

41. Badiyan SN, Markovina S, Simpson JR, Robinson CG, DeWees T, Tran DD, et al. Radiation therapy dose escalation for glioblastoma multiforme in the era of temozolomide. Int J Radiat Oncol Biol Phys 2014;90(4):877-80.

42. Mizumoto M, Tsuboi K, Igaki H, Yamamoto T, Takano $\mathrm{S}$, Oshiro Y, et al. Phase I/II trial of hyperfractionated concomitant boost proton radiotherapy for supratentorial glioblastoma multiforme. Int J Radiat Oncol Biol Phys 2010;77(1):98-105.

43. Curran WJ Jr, Scott CB, Horton J, Nelson JS, Weinstein AS, Fischbach AJ, et al. Recursive partitioning analysis of prognostic factors in three Radiation Therapy Oncology Group malignant glioma trials. J Natl Cancer Inst 1993;85(9):704-10.

44. Buatti JM, Marcus RB, Mendenhall WM, Friedman WA, Bova FJ. Accelerated hyperfractionated radiotherapy for malignant gliomas. Int J Radiat Oncol Biol Phy 1996;34(4):785-92.

45. Brada M, Sharpe G, Rajan B, Britton J, Wilkins PR,
Guerrero D, et al. Modifying radical radiotherapy in high grade gliomas; shortening the treatment time through acceleration. Int J Radiat Oncol Biol Phys 1999;43(2):287-92.

46. Niyazi M, Brada M, Chalmers AJ, Combs SE, Erridge SC, Fiorentino A, et al. ESTRO-ACROP guideline "target delineation of glioblastomas". Radiother Oncol 2016;118(1):35-42.

47. Lorentini S, Amelio D, Giri MG, Fellin F, Meliado G, Rizzotti A, et al. IMRT or 3D-CRT in glioblastoma? A dosimetric criterion for patient selection. Technol Cancer Res Treat 2013;12(5):411-20.

48. Ruben JD, Dally M, Bailey M, Smith R, McLean CA, Fedele P. Cerebral radiation necrosis: incidence, outcomes, and risk factors with emphasis on radiation parameters and chemotherapy. Int J Radiat Oncol Biol Phys 2006;65(2):499-508.

49. Rusthoven KE, Olsen C, Franklin W, KleinschmidtDeMasters BK, Kavanagh BD, Gaspar LE, et al. Favorable prognosis in patients with high-grade glioma with radiation necrosis: The University of Colorado reoperation series. Int $\mathrm{J}$ Radiat Oncol Biol Phys 2011;81(1):211-7.

50. Peca C, Pacelli R, Elefante A, Del Basso De Caro ML, Vergara P, Mariniello G, et al. early clinical and neuroradiological worsening after radiotherapy and concomitant temozolomide in patients with glioblastoma: Tumour progression or radionecrosis? Clin Neurol Neurosurg 2009;111(4):331-3. 